\title{
The Effect of the Polymer Structure in Composite Alumina/Polyetheretherketone Coatings on Corrosion Resistance, Micro-mechanical and Tribological Properties of the Ti-6Al-4V Alloy
}

\author{
Tomasz Moskalewicz, Sławomir Zimowski, Aleksandra Fiołek, Alicja Łukaszczyk, Beata Dubiel, and Łukasz Cieniek
}

(Submitted August 6, 2019; published online September 26, 2019)

\begin{abstract}
This paper describes ways of improving the tribological properties of the Ti-6Al-4V titanium alloy at room and elevated temperatures by electrophoretic deposition of $\mathrm{Al}_{2} \mathrm{O}_{3} / \mathrm{PEEK} 708$ composite coatings and postheat treatment. The microstructure of the coating components and the coatings was examined by scanning and transmission electron microscopy as well as x-ray diffractometry. The influence of cooling rate after heating of the coated alloy on the PEEK structure and coating surface topography was investigated. It was found that slow cooling with a furnace produced a semi-crystalline structure, whereas fast cooling in water generated an amorphous polymer structure. The semi-crystalline coatings exhibited a more developed surface topography than the amorphous ones. The coatings with a semi-crystalline structure revealed higher scratch resistance than the amorphous ones. The corrosion resistance of the uncoated and coated specimens was examined using electrochemical techniques in a $3.5 \mathrm{wt} \% \mathrm{NaCl}$ aqueous solution. Both coatings increased the corrosion resistance of the alloy. The friction and wear properties of the coated specimens against an alumina ball in dry sliding contact at room temperature and elevated temperatures of 150 and $260{ }^{\circ} \mathrm{C}$ at ball-on-disk were examined. Both amorphous and semi-crystalline coatings increased the wear resistance and decreased the friction coefficient of the titanium alloy at room temperature. In addition, the semi-crystalline coating was also very effective in improving the titanium alloy's tribological properties at elevated temperatures. The obtained results clearly show that the composite alumina/PEEK coatings are promising for tribological applications in mechanical engineering.
\end{abstract}

Keywords composite coating, corrosion resistance, electrophoretic deposition, wear resistance

\section{Introduction}

Polyetheretherketone (PEEK) is an organic, polyaromatic linear thermoplastic polymer, excellent for applications where thermal, chemical and combustion properties are critical to performance (Ref 1). In recent years, it has been widely used in a variety of structural and insulation applications in different environments, including moisture, due to its high chemical

This article is an invited submission to JMEP selected from presentations at The XXII Physical Metallurgy and Materials Science Conference: Advanced Materials and Technologies (AMT 2019) held June 9-12, 2019, in Bukowina Tatrzańska, Poland, and has been expanded from the original presentation.

Tomasz Moskalewicz, Aleksandra Fiolek, Beata Dubiel, and Lukasz Cieniek, Faculty of Metals Engineering and Industrial Computer Science, AGH University of Science and Technology, Czarnowiejska 66, 30-054 Kraków, Poland; Sławomir Zimowski, Faculty of Mechanical Engineering and Robotics, AGH University of Science and Technology, Mickiewicza Av. 30, 30-059 Kraków, Poland; and Alicja Lukaszczyk, Faculty of Foundry Engineering, AGH University of Science and Technology, Reymonta 23, 30-059 Kraków, Poland. Contact e-mail: tmoskale@agh.edu.pl. stability, excellent mechanical resistance, self-lubricating properties and wear resistance to elevated temperatures up to $260{ }^{\circ} \mathrm{C}$ (Ref 2-4). PEEK is also often used as a composite coating matrix material for tribological applications (Ref 5-15). Some of the possible applications of PEEK-based composites are slide bearings, gears and piston rings under various loading conditions (Ref 4, 16).

In recent years, several coating techniques have been developed to deposit PEEK-based composite coatings on metallic substrates, e.g., electrostatic powder spray (Ref 8), printing method (Ref 9-11) and electrophoretic deposition (EPD) (Ref 12-15). Among them, EPD is of growing importance in the development of composite coatings, due to the high flexibility of co-deposition of organic polymers and inorganic ceramic particles on metallic substrates (Ref 17, 18).

In our previous work, we developed the fabrication of pure PEEK coatings by EPD and post-heat treatment (Ref 19). It was found that the polymer structure, amorphous or semi-crystalline, significantly influenced the scratch resistance of the coatings, micro-mechanical and tribological properties. Semicrystalline coatings exhibited better scratch resistance, higher hardness and Young's modulus, as well as significantly higher wear resistance and a lower coefficient of friction (COF) at room temperature (RT), 150 and $260{ }^{\circ} \mathrm{C}$, compared to amorphous coatings. According to the literature (Ref 20, 21), the PEEK structure might vary from completely amorphous for samples quenched in water to partially crystalline with crystallinity up to $45 \%$ for samples crystallized at a temperature of $320^{\circ} \mathrm{C}$. However, higher load-bearing capacity is required 
under some special severe conditions (Ref 4). Thus, in addition to the polymer structure, further enhancement of mechanical and tribological performance of PEEK coatings is possible via incorporation with inorganic fillers. According to the available literature, the PEEK matrix has been filled with different particles, such as BG, HA for medical applications (Ref 22-24) and $\mathrm{Al}_{2} \mathrm{O}_{3}, \mathrm{SiO}_{2}, \mathrm{SiC}, \mathrm{Si}_{3} \mathrm{~N}_{4}, \mathrm{~h}-\mathrm{BN}, \mathrm{ZrO}_{2}$ for mechanical engineering applications (Ref $3,5-8,14-16)$. One of the most important inorganic fillers used to increase the wear resistance and load-bearing capacity of PEEK is $\mathrm{Al}_{2} \mathrm{O}_{3}$ (Ref $3,14,16$ ).

In our previous work (Ref 14), we elaborated the EPD conditions for deposition of relatively homogeneous semicrystalline $(\alpha+\gamma) \mathrm{Al}_{2} \mathrm{O}_{3} / \mathrm{PEEK} 704$ coatings on the near- $\beta$ Ti$13 \mathrm{Nb}-13 \mathrm{Zr}$ alloy for potential application in medicine. The semi-crystalline coatings showed lower COF at RT compared to the pure PEEK coatings and also improved the corrosion resistance of the near- $\beta$ Ti-13Nb-13Zr titanium alloy in Ringer's solution at a temperature of $37{ }^{\circ} \mathrm{C}$. However, the influence of the cooling rate on coating microstructure was not investigated in that work. The literature review shows that semi-crystalline PEEK coatings exhibit higher hardness, lower $\mathrm{COF}$ and wear rates, but also lower adhesion to the substrate than amorphous ones (Ref 8-11, 25-28). The main reason for the lower adhesion strength of semi-crystalline PEEK coatings is the crystallization and formation of lamellae in the interfacial region between the coating and substrate (Ref 8 ). To overcome this limitation, in this work, both amorphous and semicrystalline coatings were produced and $\mathrm{Al}_{2} \mathrm{O}_{3}$ particles were incorporated in the PEEK matrix to increase the hardness and wear resistance of the coating.

The main aim of the present work was (1) to produce $\mathrm{Al}_{2} \mathrm{O}_{3}$ / PEEK708 coatings with an amorphous and semi-crystalline structure of PEEK by EPD and subsequent heat treatment and (2) to characterize the microstructure and surface topography as well as micro-mechanical and tribological properties of the coated Ti-6Al-4V alloy. The tribological properties at RT and elevated temperatures of 150 and $260{ }^{\circ} \mathrm{C}$, as well as electrochemical corrosion resistance in the $\mathrm{NaCl}$ aqueous solution, were studied. The properties of the $\mathrm{Al}_{2} \mathrm{O}_{3} / \mathrm{PEEK} 708$-coated Ti$6 \mathrm{Al}-4 \mathrm{~V}$ alloy were compared with the PEEK 708 coated and uncoated Ti-6Al-4V alloy.

\section{Materials and Method}

A two-phase $(\alpha+\beta)$ Ti-6Al-4V titanium alloy, delivered in hot-rolled and annealed $\left(750^{\circ} \mathrm{C} / 2 \mathrm{~h}\right)$ condition by BÖHLER Edelstahl GmbH, Germany, was used as a substrate material. The microstructure of the alloy has been described elsewhere (Ref 19, 29) and consists of elongated grains of $\alpha$ phase (hexagonal close packed; hcp) up to $2 \mu \mathrm{m}$ in size and $\beta$ phase (body-centered cubic; bcc) grains with a size of about $0.5 \mu \mathrm{m}$. The specimens in the form of mirror polished disks, $25.4 \mathrm{~mm}$ in diameter and $3 \mathrm{~mm}$ thick, were used as substrates for coating deposition. Commercially available $\mathrm{Al}_{2} \mathrm{O}_{3}$ and PEEK powders have been used as coating components. $\mathrm{Al}_{2} \mathrm{O}_{3}$ powder (specified as $\alpha$ phase) was delivered by Nanostructured \& Amorphous Materials, Inc., (NanoAmor), USA. Polymer PEEK powder $\left(\right.$ VICOTE $^{\circledR} 708$ ) was delivered by Victrex Europa $\mathrm{GmbH}$, Germany. The melting point of PEEK 708 is about $372{ }^{\circ} \mathrm{C}$, and the glass transition temperature is at the level of $157{ }^{\circ} \mathrm{C}$.
The chemical composition of the suspensions used for the EPD of coatings was elaborated in our previous work (Ref 14) and consisted of $0.2 \mathrm{~g}$ of $\mathrm{Al}_{2} \mathrm{O}_{3}$ and $1.5 \mathrm{~g}$ of PEEK powder in $50 \mathrm{~mL}$ of EtOH. The stable suspensions were prepared by sonicating the mixture in an ultrasonic bath for $20 \mathrm{~min}$ and mixing for 5 min using a magnetic stirrer. The $\mathrm{pH}$ values of the suspensions were measured using a Mettler Toledo EL20 pH meter (China) and adjusted by adding citric acid $\left(\mathrm{C}_{6} \mathrm{H}_{8} \mathrm{O}_{7}\right)$ or sodium hydroxide $(\mathrm{NaOH})$. The zeta potential was measured by a Zetasizer Nano ZS 90 (Malvern Instruments Ltd., UK), at room temperature (RT, $22 \pm 1{ }^{\circ} \mathrm{C}$ ). During the deposition process, a constant voltage of $20,40,60,70,80$ and $100 \mathrm{~V}$ during a constant time of $40 \mathrm{~s}$ with a suspension temperature of RT was applied using an EX752M Multi-mode PSU power supply, UK. During EPD, half of the substrate surface was
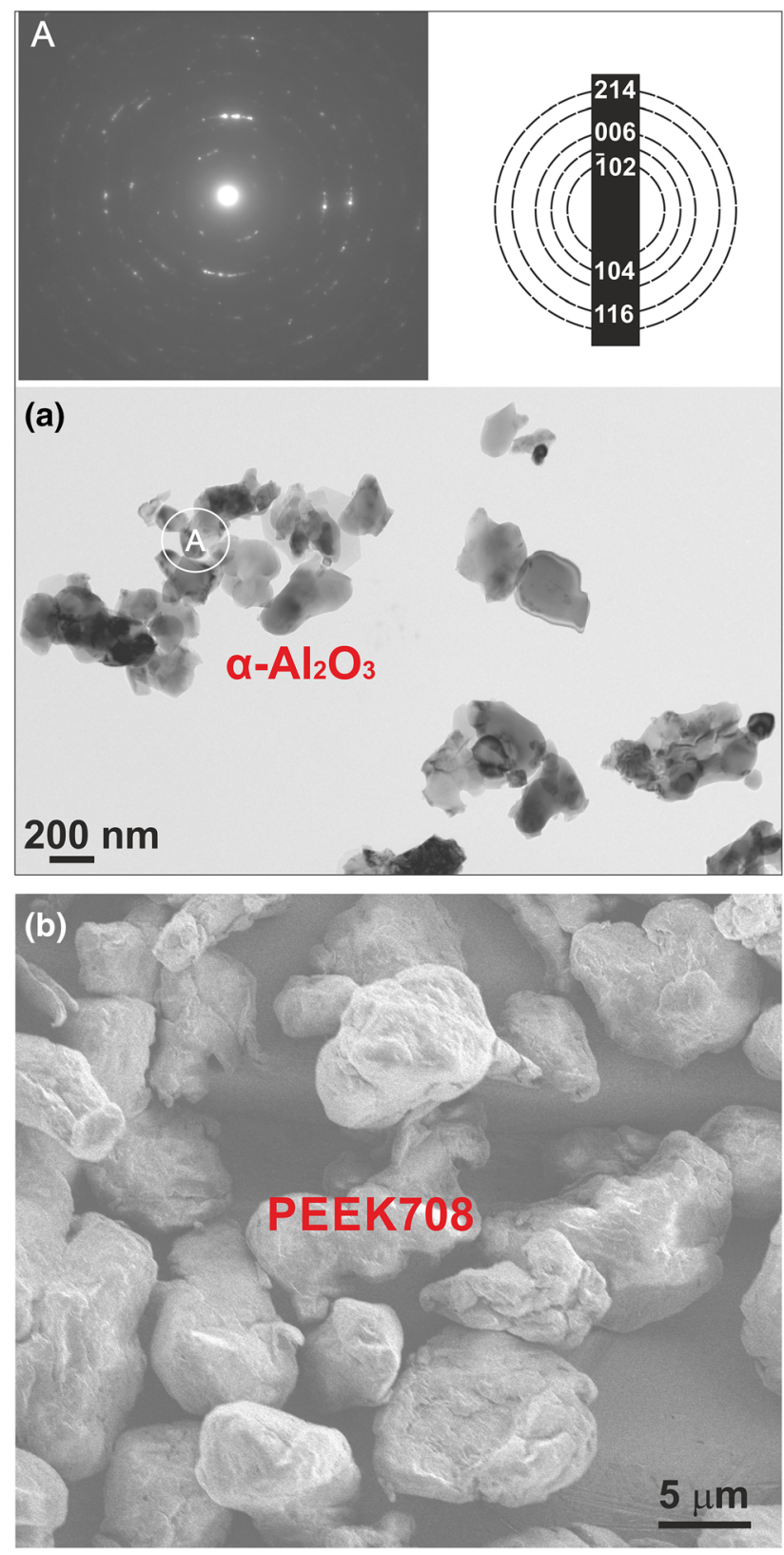

Fig. 1 Microstructure of the coating components: $\mathrm{Al}_{2} \mathrm{O}_{3}$ (a) and PEEK 708 (b) particles. TEM and SAED pattern with identification, as well as SEM secondary electron image, respectively 
exposed to deposition. The distance between the titanium alloy substrate (anode) and austenitic AISI 316L stainless steel plate with the dimensions $30 \mathrm{~mm} \times 15 \mathrm{~mm} \times 1 \mathrm{~mm}$ (cathode) was kept constant at $10 \mathrm{~mm}$.

The coated samples were dried at RT after EPD, then heated in a Carbolite-Gero LHT 4/30 laboratory oven (UK) at a temperature of $380{ }^{\circ} \mathrm{C}$ for $20 \mathrm{~min}$ (heating rate of $4.5^{\circ} \mathrm{C} / \mathrm{min}$ ) and then cooled to RT. Two cooling rates were applied, with a furnace $\left(2{ }^{\circ} \mathrm{C} / \mathrm{min}\right)$ and in water with RT.

The $\mathrm{Al}_{2} \mathrm{O}_{3}$ powder and the suspension used for EPD were investigated by transmission electron microscopy (TEM). The TEM investigation was carried out with a JEOL JEM-2010 ARP microscope (Japan) operating at $200 \mathrm{kV}$. Specimens from alumina for TEM investigation were prepared by dispersing the particles in EtOH. Afterward, the suspension was ultrasonically stirred in order to separate the agglomerated particles. Finally, a droplet of the stable appropriate suspension was placed on a copper grid covered with carbon film and dried. The same procedure was used to prepare a sample from the suspension used for EPD.

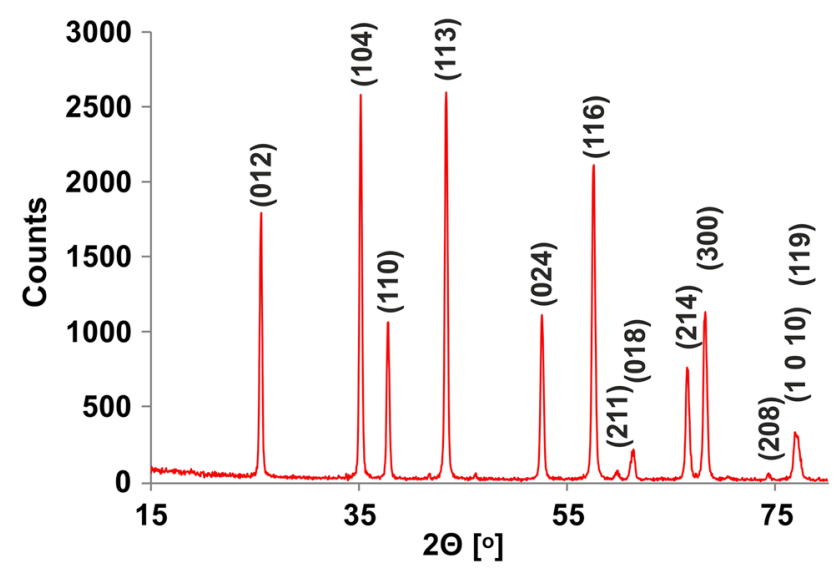

Fig. 2 XRD pattern of the $\alpha-\mathrm{Al}_{2} \mathrm{O}_{3}$ particles used for coatings deposition
The PEEK708 micro-particles and coating microstructure were characterized by scanning electron microscopy (SEM) and TEM. The SEM investigation was performed with an FEI Nova NanoSEM 450, the Netherlands. The cross-section lamella for TEM investigation of coating microstructure was prepared by a focus ion beam (FIB) using an FEI QUANTA 3D 200i device, the Netherlands. Phase composition was determined by means of selected area electron diffraction (SAED) and grazing incidence x-ray diffractometry (GIXRD). The SAED patterns were interpreted with the help of Java Electron Microscopy software (JEMS). The XRD patterns were recorded using a Panalytical Empyrean DY 1061 diffractometer (the Netherlands) with $\mathrm{Cu} \mathrm{K} \alpha$ radiation $(\lambda=1.54 \AA)$ on plan-view specimens. The phase identification was supplemented by energy-dispersive $\mathrm{x}$-ray spectroscopy, SEM-EDS and TEMEDS microanalysis.

To determine the $\mathrm{Al}_{2} \mathrm{O}_{3}$ weight content and volume fraction in the as-deposited coatings, the three as-deposited coatings were removed from the substrate to the alumina crucible and heated at $700{ }^{\circ} \mathrm{C}$ during $30 \mathrm{~min}$, with a heating rate of $10^{\circ} \mathrm{C} /$ min, in order to completely burn out the PEEK powder, as well as being weighed before and after heating. Knowing the density of the two materials provided by the suppliers (PEEK density is $1.3 \mathrm{~g} / \mathrm{cm}^{3}$ according to Victrex Europa $\mathrm{GmbH}$, Germany, and $\mathrm{Al}_{2} \mathrm{O}_{3}$ density is $3.9 \mathrm{~g} / \mathrm{cm}^{3}$ according to NanoAmor, USA), the $\mathrm{Al}_{2} \mathrm{O}_{3}$ volume fraction in the coatings was calculated.

The coating thickness was measured by contact profilometry. The measurements were taken on a $15 \mathrm{~mm}$ trace length starting in the uncoated area and finishing on the coating surface. The difference in the recorded height in these areas was equal to the coating thickness.

The surface topography of the coatings was investigated by tapping-mode atomic force microscopy (AFM). AFM imaging was performed with a Veeco Dimension ${ }^{\circledR}$ Icon $^{\mathrm{TM}}$ SPM microscope, USA, in ScanAsyst in the air mode using ScanAsyst-Air tips (Veeco), tip radius 2-12 nm. AFM images of the coating's surface topography were acquired in scanning areas up to $40 \mu \mathrm{m} \times 40 \mu \mathrm{m}$.

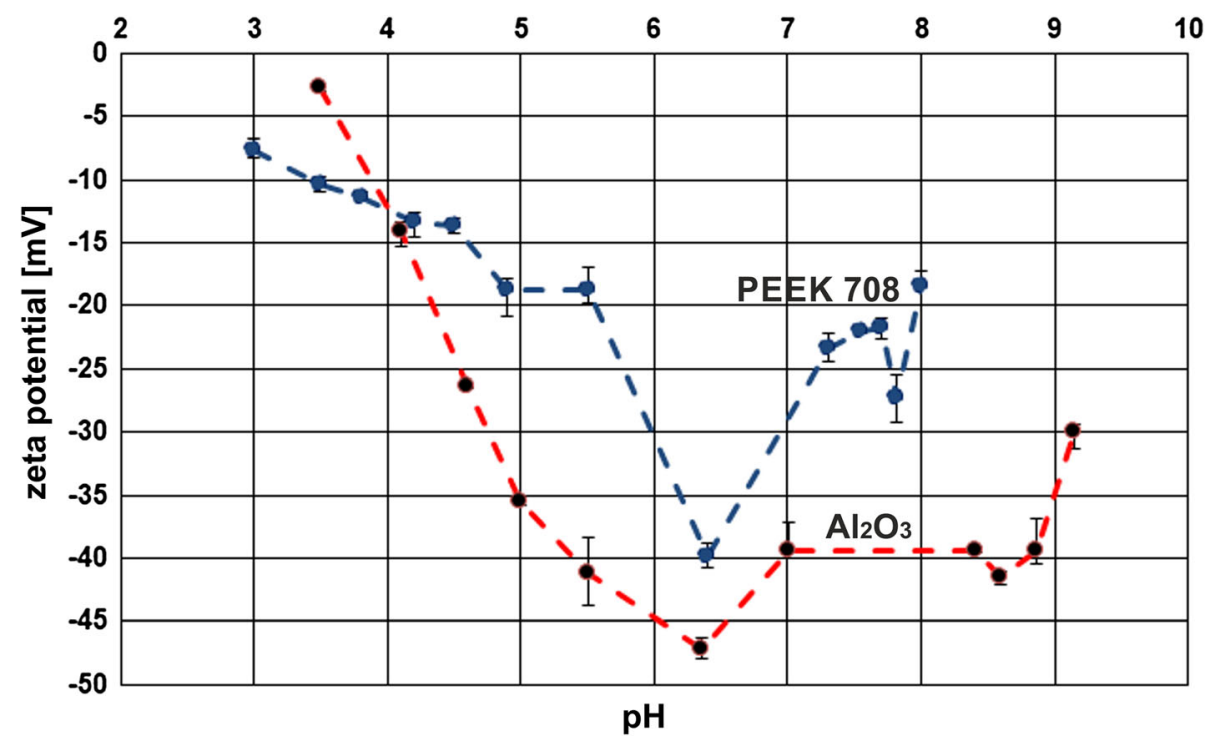

Fig. 3 Zeta potential of the $\alpha-\mathrm{Al}_{2} \mathrm{O}_{3}$ and PEEK 708 particles as a function of pH for the suspension composed of $0.2 \mathrm{~g} \alpha-\mathrm{Al}_{2} \mathrm{O}_{3}$ in $50 \mathrm{~mL}$ of EtOH and $0.02 \mathrm{~g}$ PEEK708 in $50 \mathrm{~mL}$ of EtOH, respectively 


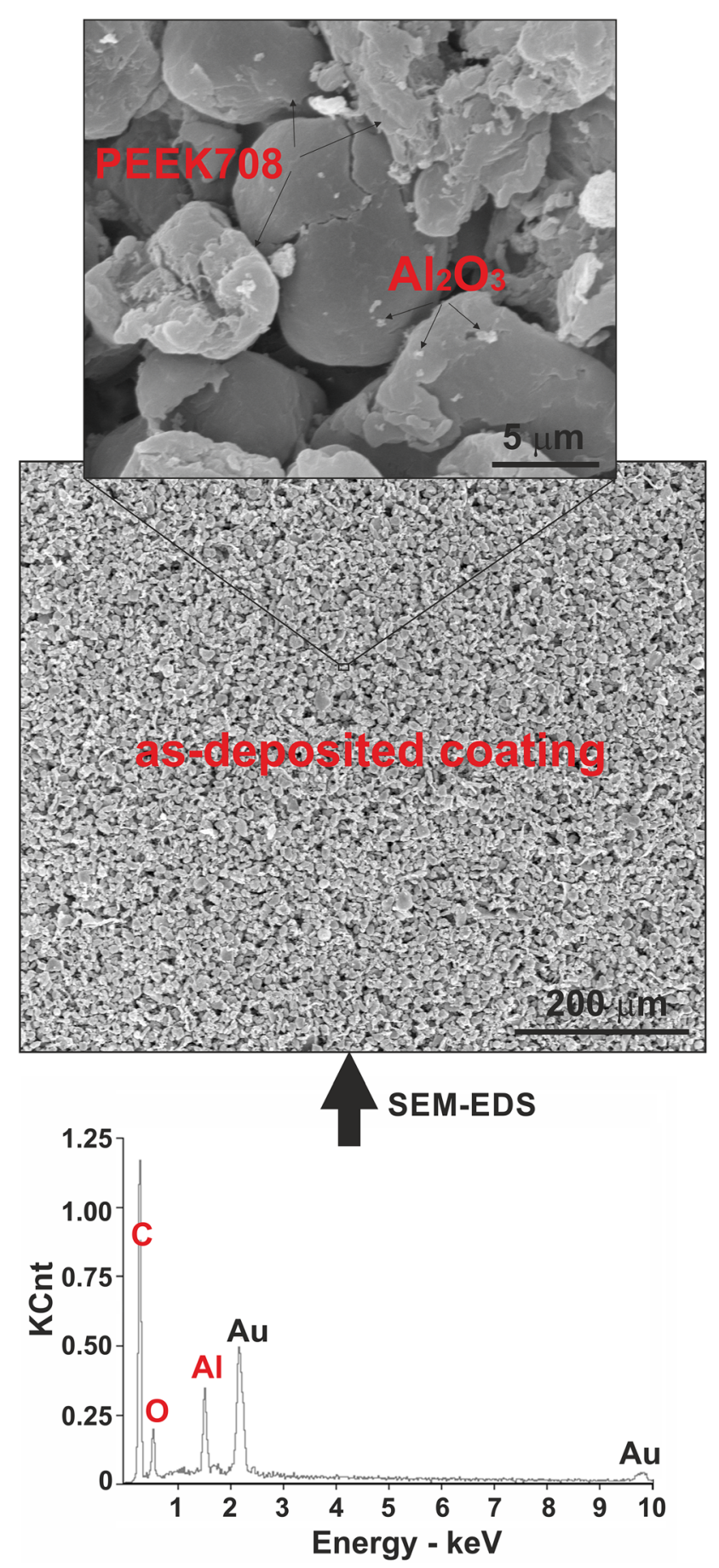

Fig. 4 Morphology of the as-deposited $\mathrm{Al}_{2} \mathrm{O}_{3} / \mathrm{PEEK} 708$ coating with an enlarged detail on the top. SEM secondary electron images, plan-view specimen. SEM-EDS spectrum was taken from the whole area of this figure. Au peaks come from the evaporation of the sample

An Autolab PGSTAT302 N potentiostat, the Netherlands, was used to carry out electrochemical studies of the samples. The corrosion behavior was analyzed by immersing the samples in a 3.5 wt.\% $\mathrm{NaCl}$ aqueous solution at RT. A classical three-electrode cell, where the working electrode was a titanium alloy, was used for the measurements. Potentials were measured versus a saturated calomel electrode (SCE), with the counter electrode being made of platinum wire.
Electrochemical measurements were taken in solutions. A scan rate of $1 \mathrm{mV} / \mathrm{s}$ in the potential range from -1.3 to $+2.2 \mathrm{~V}$ was used for the linear sweep voltamperometry curves. For the EIS measurements, the amplitude was $10 \mathrm{mV}$ and the frequency was from $10^{5}$ to $10^{-3} \mathrm{~Hz}$. The EIS data were fitted by using the ZView software. Minimizing errors was performed using the Chi-squared criteria for fitting the experimental data of the EIS.

The microhardness and elastic modulus of the coated Ti6Al-4V alloy were measured on plan-view specimens with a CSM Instruments Micro-Combi Tester (MCT), Switzerland, using the instrumented indentation technique. A Vickers indenter was applied with a maximum load of $100 \mathrm{mN}$ and a dwell time of $15 \mathrm{~s}$. The reported hardness and elastic modulus values were averaged based on ten separated indents.

The scratch resistance of the coatings was investigated by means of MCT with a Rockwell C spherical diamond stylus with a $200 \mu \mathrm{m}$ tip radius. The progressive mode of the scratch test with a continuously increasing load from 0.01 to $30 \mathrm{~N}$ and movement of the sample at a speed of $5 \mathrm{~mm} / \mathrm{min}$ and $5 \mathrm{~mm}$ of a scratch length were applied. The values of the loads causing cohesive or adhesive failure were determined by surface observation, the penetration depth of the indenter and the friction force signal analysis. The imaging of the alteration in the coating surface at different loads was obtained with light microscopy (LM) and SEM. Average values of the critical loads were calculated based on three scratches for each specimen.

A ball-on-disk apparatus (made in the Institute for Sustainable Technologies - National Research Institute, Poland) was used to investigate the friction and wear properties of the coated alloy. The tests were carried out in dry sliding contact with alumina balls of $6 \mathrm{~mm}$ in diameter at RT as well as at elevated temperatures of 150 and $260{ }^{\circ} \mathrm{C}$. Experiments were conducted with the following test parameters: $5 \mathrm{~N}$ normal load, $0.05 \mathrm{~m} / \mathrm{s}$ sliding speed, $3 \mathrm{~mm}$ radius of the wear track and the sliding distance of $2000 \mathrm{~m}$. The experiments were repeated three times for each specimen. Prior to each test, the samples and balls were cleaned with ethanol. The specific wear rate of the samples, $\mathrm{W}_{\mathrm{V}}$, was calculated using the equation:

$W_{V}=V / F_{\mathrm{n}} \cdot s$

where $F_{\mathrm{n}}$ is the applied load, $s$ is the sliding distance and $V$ is the worn volume of the sample. The worn volume was calculated from the profiles of the groove cross section, which were measured using a stylus profilometer.

\section{Results}

\subsection{EPD, Microstructure and Surface Topography of Coatings}

Representative electron microscopy images of the particles used for EPD are shown in Fig. 1(a) and (b). The $\mathrm{Al}_{2} \mathrm{O}_{3}$ particles with equivalent circle diameter (ECD) in the range of $50-250 \mathrm{~nm}$ had spherical and irregular shapes (Fig. 1a). Analysis of the SAED and XRD patterns taken from the $\mathrm{Al}_{2} \mathrm{O}_{3}$ particles revealed the presence of $\alpha-\mathrm{Al}_{2} \mathrm{O}_{3}$ (rhombohedral primitive, space group $\mathrm{R}-3 \mathrm{cH}$ ) phase (SAED and GIXRD patterns in Fig. 1(a) and in 2, respectively), while TEM-EDS microanalysis confirmed the presence of $\mathrm{Al}$ and $\mathrm{O}$ only. The PEEK708 particles with ECD in the range of $4-15 \mu \mathrm{m}$ exhibited globular and flattened morphology (Fig. 1b). 

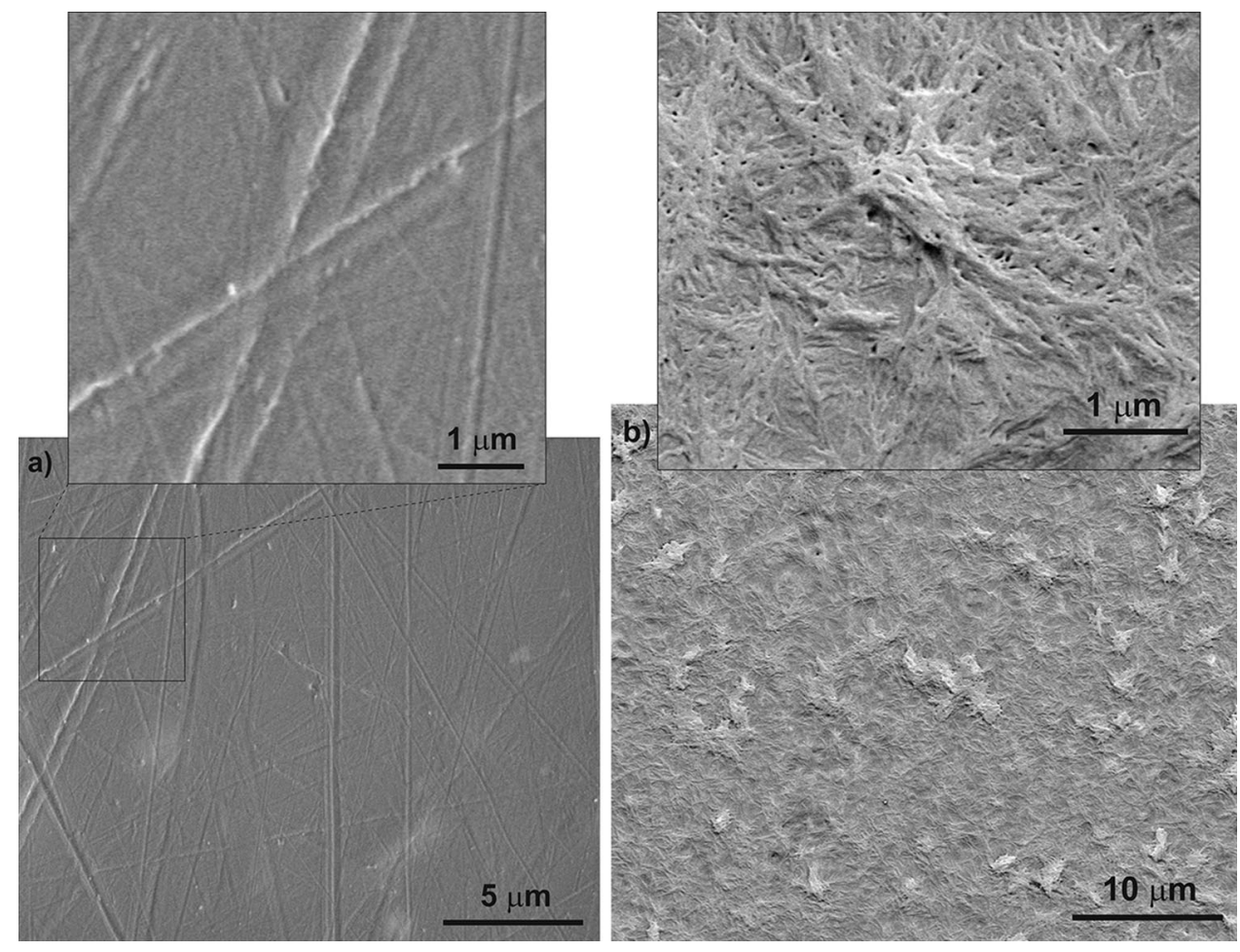

Fig. 5 Microstructure of the $\mathrm{Al}_{2} \mathrm{O}_{3} / \mathrm{PEEK} 708$ coatings after heating at $380{ }^{\circ} \mathrm{C}$ during $20 \mathrm{~min}$ and cooling in water (a) and with a furnace (b). SEM secondary electron (a) and backscattered electron (b) images

PEEK708 particles exhibited mainly an amorphous structure, as it was shown in our previous work (Ref 19). Only very small crystalline peaks were present in the XRD pattern.

To deposit an $\mathrm{Al}_{2} \mathrm{O}_{3} / \mathrm{PEEK} 708$ composite coating, we used a suspension with a chemical composition elaborated for the EPD of $(\alpha+\gamma) \mathrm{Al}_{2} \mathrm{O}_{3} /$ PEEK704 polymer coatings in our previous study (Ref 14), which consisted of $0.2 \mathrm{~g}$ of $\mathrm{Al}_{2} \mathrm{O}_{3}$ and $1.5 \mathrm{~g}$ of PEEK powder in $50 \mathrm{~mL}$ of EtOH. The codeposition mechanism of the $\mathrm{Al}_{2} \mathrm{O}_{3}$ and PEEK 704 particles and EPD kinetics was investigated in detail in our previous paper (Ref 14). However, in the present work, different $\mathrm{Al}_{2} \mathrm{O}_{3}$ $\left(\alpha-\mathrm{Al}_{2} \mathrm{O}_{3}\right)$ and PEEK (PEEK 708) were used and we focused on the measurement of the zeta potential vs $\mathrm{pH}$ of the suspension to confirm the suspension stability. In contrast to the $\alpha+\gamma$ $\mathrm{Al}_{2} \mathrm{O}_{3}$ particles, the $\alpha-\mathrm{Al}_{2} \mathrm{O}_{3}$ particles investigated in this work exhibited negative zeta potential in EtOH through the investigated $\mathrm{pH}$ range of 3.5-9.2. The highest absolute value of zeta potential, higher than $35 \mathrm{mV}$, was measured for the suspension with a $\mathrm{pH}$ in the range 5.0-8.8 composed of $0.2 \mathrm{~g} \mathrm{Al}_{2} \mathrm{O}_{3}$ in $50 \mathrm{~mL}$ of $\mathrm{EtOH}$ (Fig. 3). We suppose that these differences in zeta potential of both $\mathrm{Al}_{2} \mathrm{O}_{3}$ particles, i.e., investigated in the previous study and in this study, might be due to the presence of high amounts of nanocrystalline $\gamma-\mathrm{Al}_{2} \mathrm{O}_{3}$ particles, while in this work we use the $\alpha-\mathrm{Al}_{2} \mathrm{O}_{3}$ particles with a larger size of 50$250 \mathrm{~nm}$.
Similar to the PEEK704 investigated in our previous work (Ref 14), the PEEK708 particles also had a negative charge in EtOH. The highest zeta potential (around - $40 \mathrm{mV}$ ) was found for the suspension of PEEK708 in EtOH with $\mathrm{pH}=6.4$. During TEM observation of the suspension used for EPD, the $\mathrm{Al}_{2} \mathrm{O}_{3}$ particles occurred mainly separately or formed agglomerates. Based on zeta potential measurements and TEM investigation, the EPD mechanism of $\alpha-\mathrm{Al}_{2} \mathrm{O}_{3}$ and PEEK708 particle codeposition was different from the one for the co-deposition of $\alpha+\gamma \mathrm{Al}_{2} \mathrm{O}_{3}$ and PEEK 704 particles described in our previous work (Ref 14), which consisted of electrostatic interaction of $\alpha+\gamma \quad \mathrm{Al}_{2} \mathrm{O}_{3}$ particles with negatively charged PEEK704 particles and the formation of PEEK-alumina composite particles in the suspension. We suppose that the EPD mechanism in this work consisted of independent deposition of two types of particles on the anode.

The macroscopically homogeneous coatings were obtained from the suspension with a chemical composition of $1.5 \mathrm{~g}$ PEEK 708, $0.2 \mathrm{~g}$ of $\alpha-\mathrm{Al}_{2} \mathrm{O}_{3}$ and $50 \mathrm{~mL}$ of EtOH with $\mathrm{pH}=7.3$, without base or acid addition, at a constant voltage range of 40-90 $\mathrm{V}$ with the best macroscopic homogeneity at a voltage of $70 \mathrm{~V}$. Accordingly, smaller voltages resulted in the formation of thin coatings of uneven thickness, while the coatings deposited at higher voltage values were usually too thick and also uneven and showed a tendency to crack and 

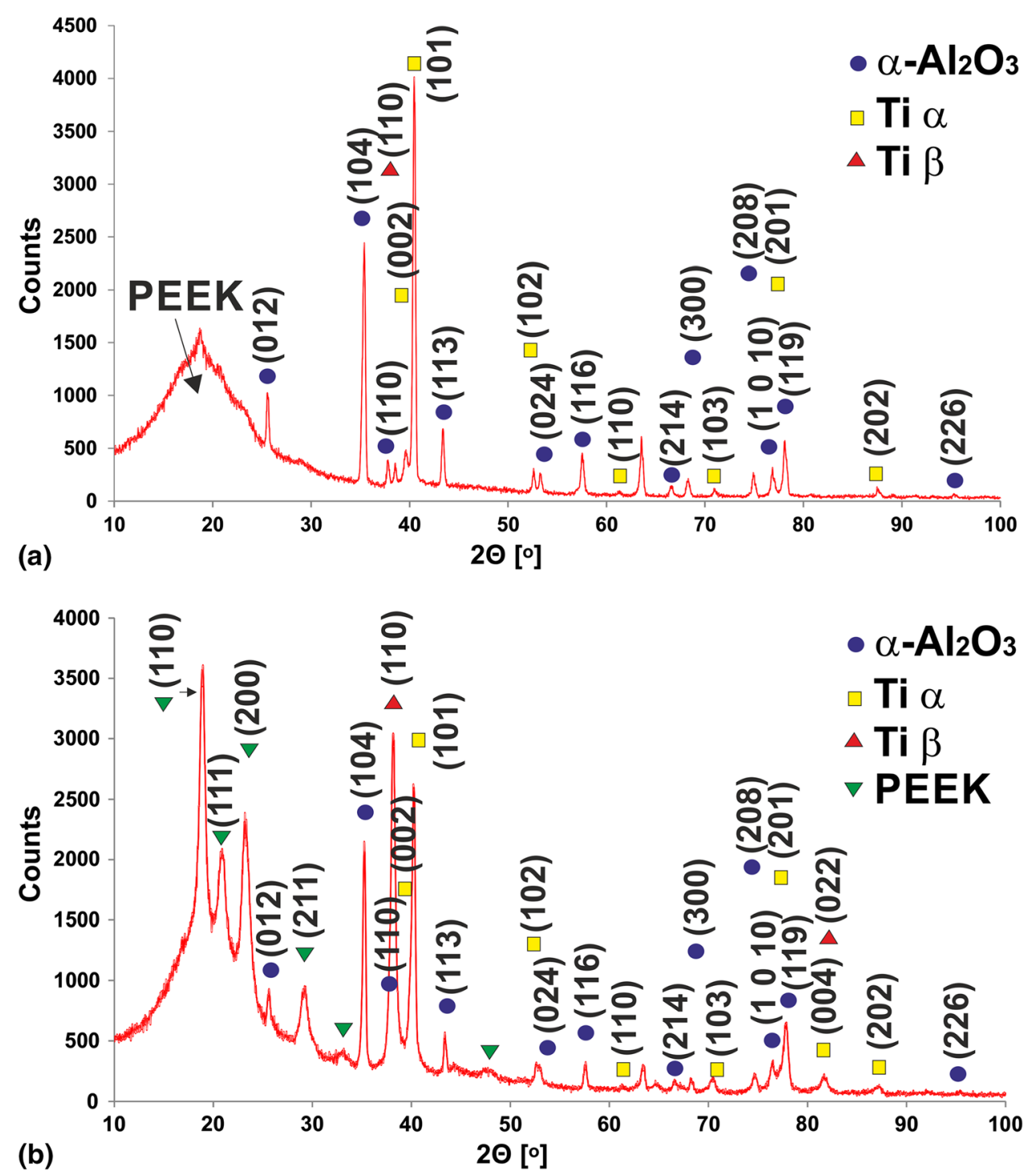

Fig. 6 XRD patterns of the $\mathrm{Al}_{2} \mathrm{O}_{3} / \mathrm{PEEK} 708$ coating on the Ti-6Al-4V alloy after heating at $380{ }^{\circ} \mathrm{C}$ during 20 min and cooling in water (a) and with a furnace (b)

delaminate. SEM investigation confirmed the homogeneous distribution of PEEK708 and $\alpha-\mathrm{Al}_{2} \mathrm{O}_{3}$ particles on the titanium alloy substrate (Fig. 4). Moreover, the presence of $\mathrm{Al}_{2} \mathrm{O}_{3}$ particles within the coating was confirmed by SEM-EDS microanalysis. The weight content and volume fraction of alumina in the as-deposited coatings deposited at voltage of $70 \mathrm{~V}$ during $20 \mathrm{~min}$ were determined as $13.3 \pm 2.5 \mathrm{wt} \%$ and $4.9 \pm 1$ vol. $\%$, respectively. The as-deposited coatings consisted of loosely spaced particles of both types and their adhesion to the substrate was poor. Therefore, heat treatment was necessary to densify the coatings and to increase their adhesion to the underlying substrate. Two different heat treatment routes were applied. In both, the coated samples were heated above the melting point of PEEK708 (i.e., temperature of $380{ }^{\circ} \mathrm{C}$ for $20 \mathrm{~min}$ ), and then, two different cooling rates were applied: (1) fast cooling in water at RT and (2) slow cooling with a furnace $\left(2{ }^{\circ} \mathrm{C} / \mathrm{min}\right)$. As a result of heat treatment, the morphology of PEEK changed from granular particles into a dense and continuous coating matrix (Fig. 5). The cooling rate after heating significantly affected the PEEK structure. As a result of fast cooling, an amorphous structure of the polymer was obtained, while after slow cooling a semicrystalline structure was formed (Fig. 6). Characteristic lines, indicating the beginning of crystallization, were present on the amorphous coating surface (Fig. 5a). The same effect was observed for an amorphous pure PEEK708 coating and described in our previous work (Ref 19). In both types of coatings, the $\alpha-\mathrm{Al}_{2} \mathrm{O}_{3}$ particles were embedded in the PEEK matrix. A representative TEM image of the amorphous $\mathrm{Al}_{2} \mathrm{O}_{3}$ / PEEK708 coating is shown in Fig. 7. The structure of PEEK after slow cooling after annealing above the melting temperature was described in detail in our previous works on the example of PEEK704 (Ref 14, 15, 30). The semi-crystalline coating exhibited slightly higher thickness of $95 \mu \mathrm{m}$ than the amorphous ones with a thickness of $80 \mu \mathrm{m}$. 


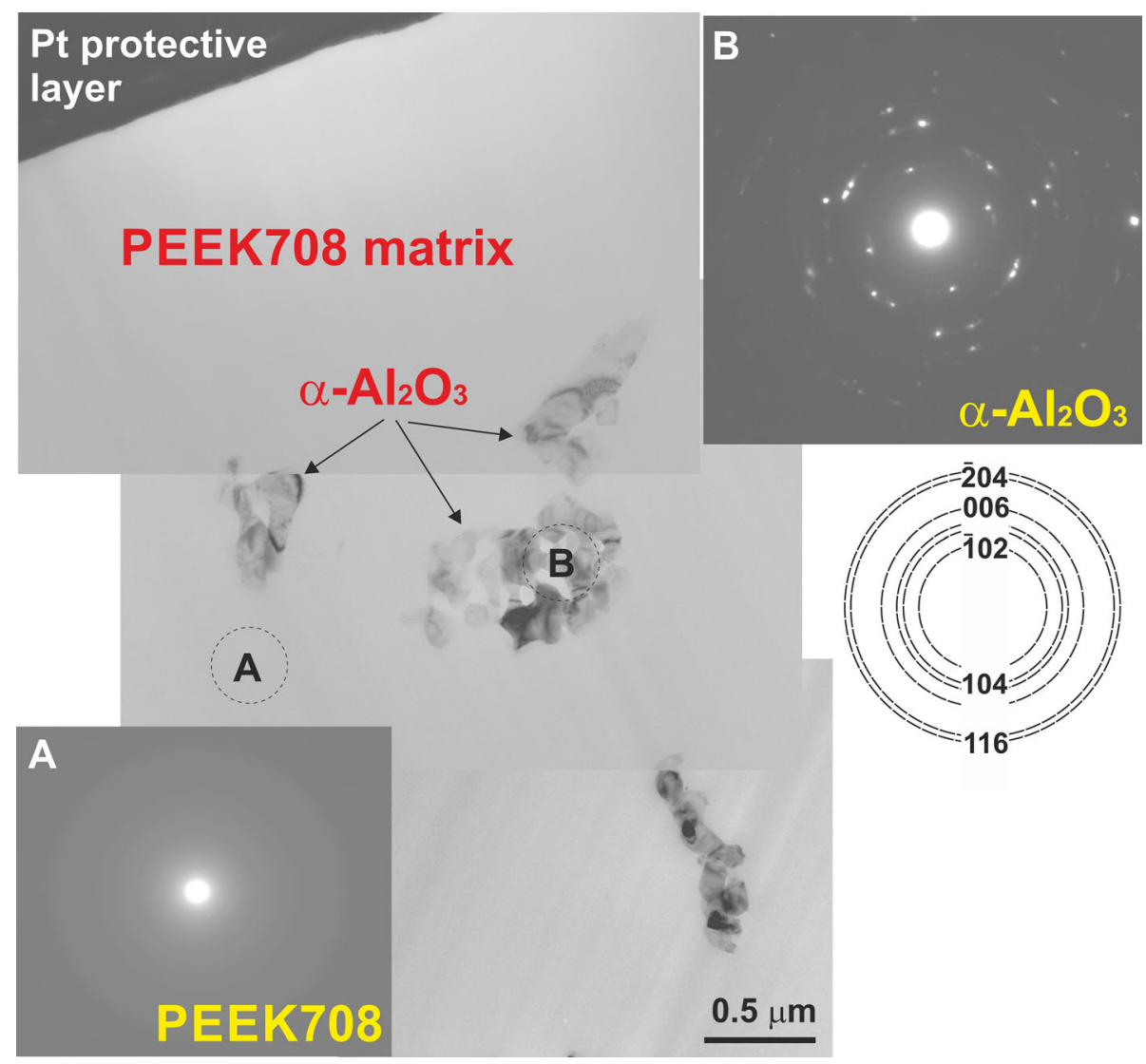

Fig. 7 TEM micrograph of the $\mathrm{Al}_{2} \mathrm{O}_{3} / \mathrm{PEEK} 708$ coating after heating at $380{ }^{\circ} \mathrm{C}$ during $20 \mathrm{~min}$ and cooling in water as well as SAED patterns taken from the areas marked by a circle

Table 1 Selected parameters of the surface topography of the amorphous and semi-crystalline $\mathrm{Al}_{2} \mathrm{O}_{3} / \mathrm{PEEK}_{\mathrm{K}} \mathrm{Co}$ coatings

\begin{tabular}{lcccc}
\hline Parameter/coating type & $\boldsymbol{R}_{\mathbf{a}}, \mathbf{n m}$ & $\boldsymbol{R}_{\mathbf{q}}, \mathbf{n m}$ & $\boldsymbol{R}_{\mathbf{t}}, \mathbf{n m}$ & $\mathbf{I S A D}, \mathbf{\%}$ \\
\hline Amorphous & $20.4 \pm 7.6$ & $26.6 \pm 10.6$ & $214.0 \pm 48.1$ & $0.1 \pm 0.03$ \\
Semi-crystalline & $117.0 \pm 48.5$ & $161.1 \pm 87.4$ & $1273.4 \pm 749.5$ & $7.0 \pm 2.64$ \\
\hline
\end{tabular}

The cooling rate after annealing also influenced the surface topography of the coatings. The values of basic surface topography parameters, the average roughness $\left(R_{\mathrm{a}}\right)$, the mean square roughness $\left(R_{\mathrm{q}}\right)$, total roughness $\left(R_{\mathrm{t}}\right)$ and image surface area difference (ISAD) are shown in Table 1. It was observed that the amorphous coatings were smoother and the surface of the coatings was poorly developed (Fig. 8a). In contrast, the surface of the semi-crystalline coatings was more developed and rougher (Fig. $8 \mathrm{~b}$ ) due to the presence of spherulites on the coating surface. In comparison with the pure PEEK708 coatings (Ref 19), the surface topography parameters of pure polymeric and $\mathrm{Al}_{2} \mathrm{O}_{3} / \mathrm{PEEK}$ composite coatings with an amorphous structure developed by cooling in water after heating were similar. However, in the case of the coatings with a semi-crystalline structure developed by cooling with a furnace after heating, the $\mathrm{Al}_{2} \mathrm{O}_{3} / \mathrm{PEEK}$ composite coatings exhibited much better developed surface topography. It is speculated that the presence of alumina particles inhibited the growth of spherulites in the composite coatings during heat treatment.

\subsection{Electrochemical Corrosion Resistance}

Figure 9(a) shows the evolution of the open-circuit potential (OCP) for the uncoated as well as amorphous and semicrystalline $\mathrm{Al}_{2} \mathrm{O}_{3} / \mathrm{PEEK} 708$-coated alloy. The OCPs were measured during a 22-h-long immersion test before the polarization curves were captured. It was found that the OCP reached the highest value of $0.32 \mathrm{~V}$ for the uncoated alloy. The potential value of the semi-crystalline $\mathrm{Al}_{2} \mathrm{O}_{3} / \mathrm{PEEK} 708$ coated alloy at the beginning of the measurement equaled $1 \mathrm{~V}$ and changed in time, constantly decreasing its value till the moment when it reached about $0.20 \mathrm{~V}$ after approx. 28,000 s. Similar plots, but with slightly lower values of potentials (0.29-0.14 V), were observed for the amorphous $\mathrm{Al}_{2} \mathrm{O}_{3} / \mathrm{PEEK} 708$-coated 
alloy. The decrease in stationary potential can be connected with the presence of $\mathrm{Al}_{2} \mathrm{O}_{3}$ in the coating microstructure (Ref 31).

Potentiodynamic polarization testing was carried out in order to gain a deeper understanding of the corrosion properties of the uncoated and coated alloy (Fig. 9b). It is possible to define the corrosion rate by limiting the current density that passes through the passivating film, in which case it becomes a measure of the film's protective performance (Ref 32). The passive properties of the Ti-6Al-4V alloy are mainly due to the presence of titanium-based compounds in the passive film (Ref $33)$. The passive current density $\left(i_{\mathrm{p}}\right)$ was reduced from $5 \mu \mathrm{A} /$ $\mathrm{cm}^{2}$ for the uncoated sample to 0.52 and $0.03 \mu \mathrm{A} / \mathrm{cm}^{2}$ for the amorphous and semi-crystalline $\mathrm{Al}_{2} \mathrm{O}_{3}$ /PEEK708-coated ones, respectively. Moreover, the cathodic-anodic transition equaled $-0.49 \mathrm{~V}$ for the uncoated alloy, $-0.24 \mathrm{~V}$ for the semicrystalline $\mathrm{Al}_{2} \mathrm{O}_{3} / \mathrm{PEEK} 708$ and $-0.092 \mathrm{~V}$ for the amorphous $\mathrm{Al}_{2} \mathrm{O}_{3} / \mathrm{PEEK} 708$ coatings. This polarization curve shift indicates a great improvement in corrosion resistance thanks to these coatings acting as protective layers against corrosion. Additionally, significantly lower current density achieved for the semi-crystalline coating indicated better corrosion resistance compared to the amorphous one.

Figure 10(a), (b), and (c) shows the electrochemical impedance spectroscopy (EIS) spectra of the uncoated and coated alloy in the $\mathrm{NaCl}$ solution presented as a Nyquist plot (Fig. 10a) and a Bode plot (Fig. 10b and c). A higher Z modulus at lower frequency in the Bode impedance plot

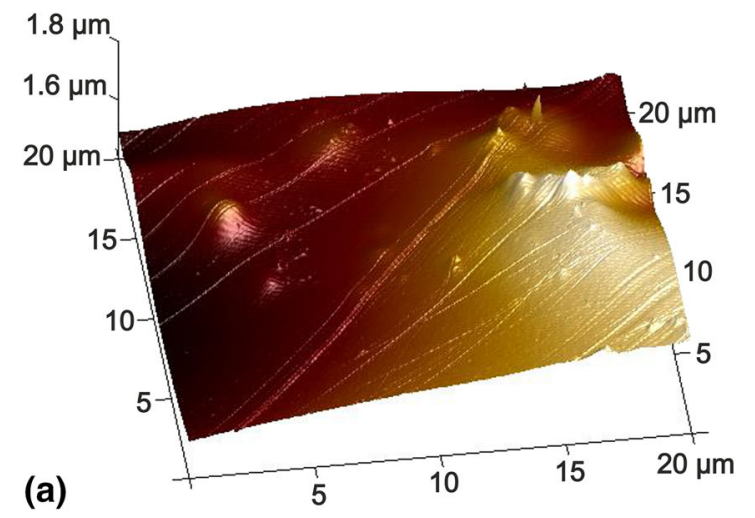

(b)

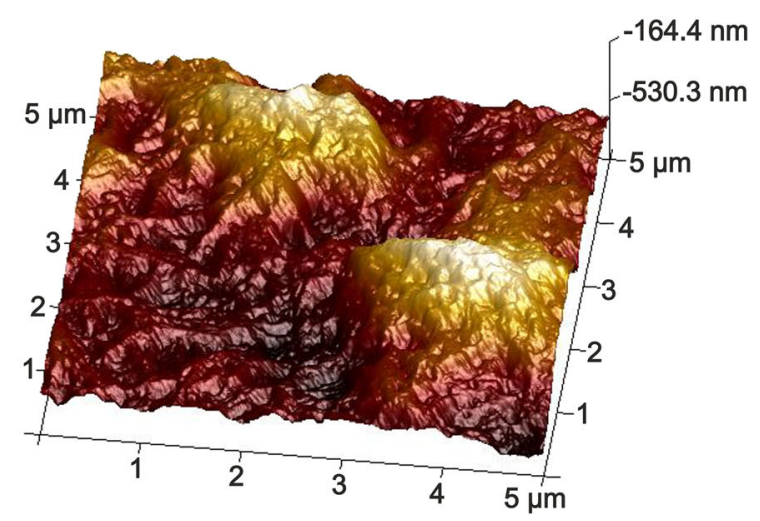

Fig. 8 Surface topography of the amorphous (a) and semicrystalline (b) $\mathrm{Al}_{2} \mathrm{O}_{3} /$ PEEK 708 coating on the Ti-6Al-4V alloy, AFM indicated a better corrosion resistance of the coated alloy (Fig. 10b). The uncoated and coated alloy showed a highly capacitive behavior from medium to low frequencies (Fig. 10c), indicating that a stable film was formed on the substrate. The equivalent circuit shown in Fig. 10(d) was used to fit the EIS data. According to the double-layer model for the surface coating, the equivalent circuit consisted of the electrolyte resistance (R1), the coating resistance (R2) and the constant phase elements (CPE). A good fit between the experimental and simulated results was achieved, and the circuit parameters are listed in Table 2.

The amorphous and semi-crystalline $\mathrm{Al}_{2} \mathrm{O}_{3} / \mathrm{PEEK} 708$ coatings on the Ti-6Al-4V alloy had a similar CPE-P value which was the closest to the capacitance (typical of passive coatings). The resistance (R2) of the amorphous and semi-crystalline $\mathrm{Al}_{2} \mathrm{O}_{3} / \mathrm{PEEK} 708$ coatings on the Ti-6Al-4V alloy was higher than that of the uncoated alloy, which suggested that the coated alloy had better corrosion resistance than the uncoated one. Additionally, the significantly higher parameters: CPE-P and $\mathrm{R} 2$, of the semi-crystalline coating indicated better corrosion resistance compared to the amorphous coating and uncoated alloy. These results were accordant with the polarization investigations.
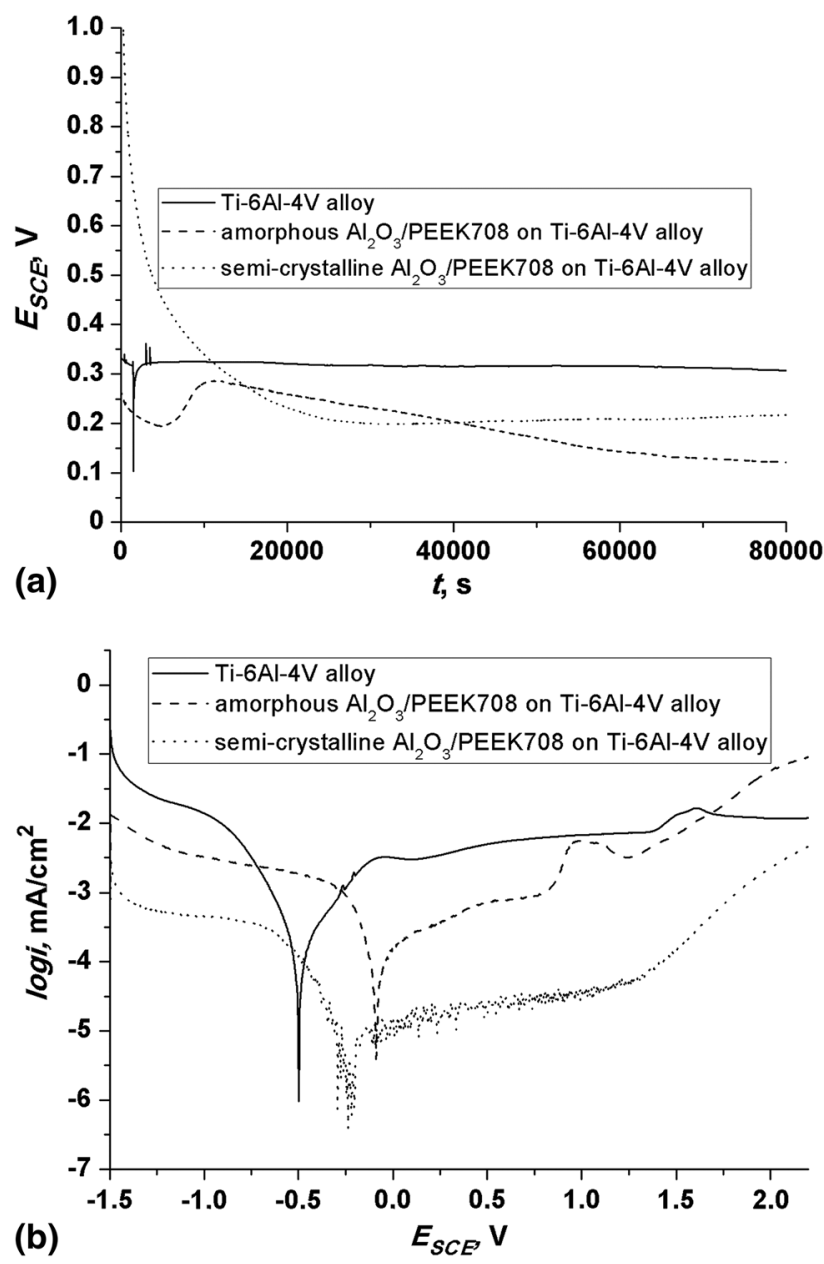

Fig. 9 Electrochemical measurements of the uncoated and coated Ti-6Al-4V alloy in $\mathrm{NaCl}$ solution at $25{ }^{\circ} \mathrm{C}$, (a) evolution of the corrosion potential vs. time and (b) polarization curves at $1 \mathrm{mV} / \mathrm{s}$ 

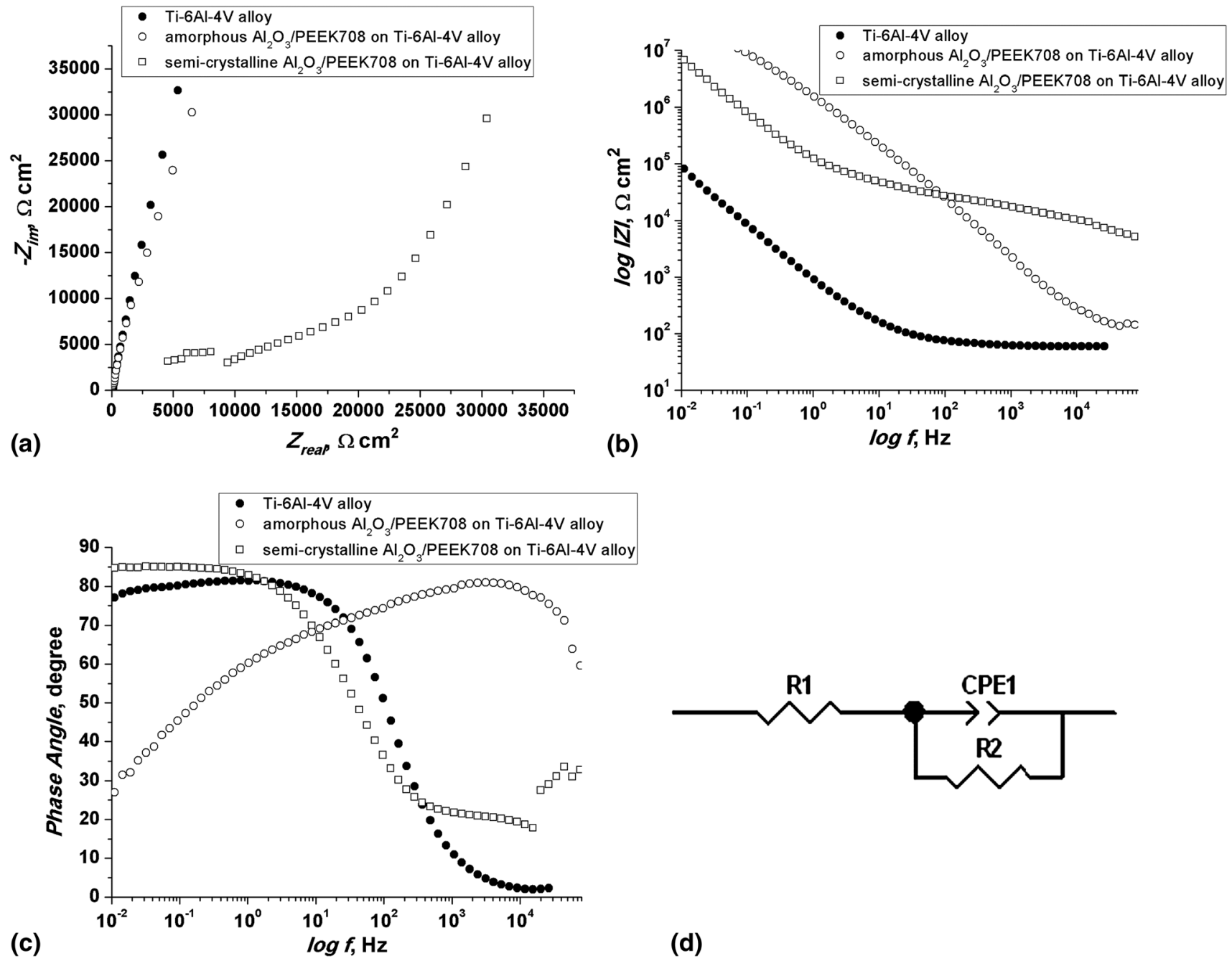

Fig. 10 Electrochemical impedance curves of the uncoated and $\mathrm{Al}_{2} \mathrm{O}_{3} / \mathrm{PEEK} 708$-coated Ti-6Al-4V alloy in NaCl solution, (a) Nyquist impedance plot, (b) bode impedance plot, (c) bode phase angle plot, (d) equivalent circuit used for fitting EIS data of investigated samples

Table 2 Chi-square $\left(\chi^{2}\right)$ values obtained by fitting the equivalent electrical circuit with ZView software and electrochemical parameters for the uncoated and coated titanium alloy

\begin{tabular}{|c|c|c|c|c|c|}
\hline Samples & $\chi^{2}$ & $R_{1}, \Omega^{*} \mathrm{~cm}^{2}$ & CPE-T, Fs $^{\mathrm{n}-1} \mathrm{~cm}^{-2}$ & CPE-P & $R_{2}, \Omega^{*} \mathbf{c m}^{2}$ \\
\hline Ti-6Al-4V alloy & 0.001 & 0.1999 & $3.0272 * 10^{-5} \pm 6.9365 * 10^{-8}$ & $0.91 \pm 0.0006$ & $4.2551 * 10^{6} \pm 72,812$ \\
\hline $\begin{array}{l}\text { Amorphous } \mathrm{Al}_{2} \mathrm{O}_{3} / \mathrm{PEEK} 708 \\
\text { coating on Ti- } 6 \mathrm{Al}-4 \mathrm{~V} \text { alloy }\end{array}$ & 0.005 & $22.34 \pm 0.2459$ & $6.5535 * 10^{-8} \pm 2.4477 * 10^{-9}$ & $0.82 \pm 0.0053$ & $2.7476 * 10^{7} \pm 1.5643 * 10^{6}$ \\
\hline $\begin{array}{l}\text { Semi-crystalline coating } \mathrm{Al}_{2} \mathrm{O}_{3} / \\
\text { PEEK } 708 \text { on Ti-6Al-4V alloy }\end{array}$ & 0.006 & $30.32 \pm 0.1352$ & $1.4497 * 10^{-7} \pm 4.3929 * 10^{-9}$ & $0.90 \pm 0.0076$ & $1.238 * 10^{16} \pm 2.8703 * 10^{15}$ \\
\hline
\end{tabular}

\subsection{Scratch Resistance, Micro-mechanical and Tribological Properties}

The influence of the PEEK708 polymer structure on the coated alloy's scratch resistance, micro-mechanical and tribological properties has been analyzed. The highest scratch resistance was demonstrated by the $\mathrm{Al}_{2} \mathrm{O}_{3} /$ PEEK708 coating with a semi-crystalline structure of the polymer, for which some cohesive cracks were found at an average load Lc1 $=26 \mathrm{~N}$ (Fig. 11a). A lower scratch resistance was found in the composite coating with the amorphous polymer structure, in which the cohesive cracks occurred at an average load Lc1 $=19 \mathrm{~N}$ (Fig. 11b). Despite the amorphous structure of this coating, the formation of these cracks was accompanied by a distinct acoustic emission, which is a characteristic signal when brittle materials crack. No adhesive damage of the coatings was found in the range up to a $30 \mathrm{~N}$ load of a diamond stylus.

In comparison with the scratch resistance of the pure PEEK708 coatings with amorphous and semi-crystalline structures developed in our previous study (Ref 19), the alumina 

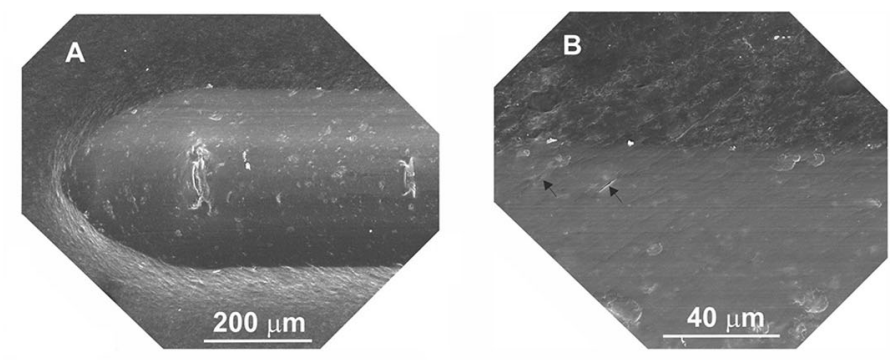

(a)
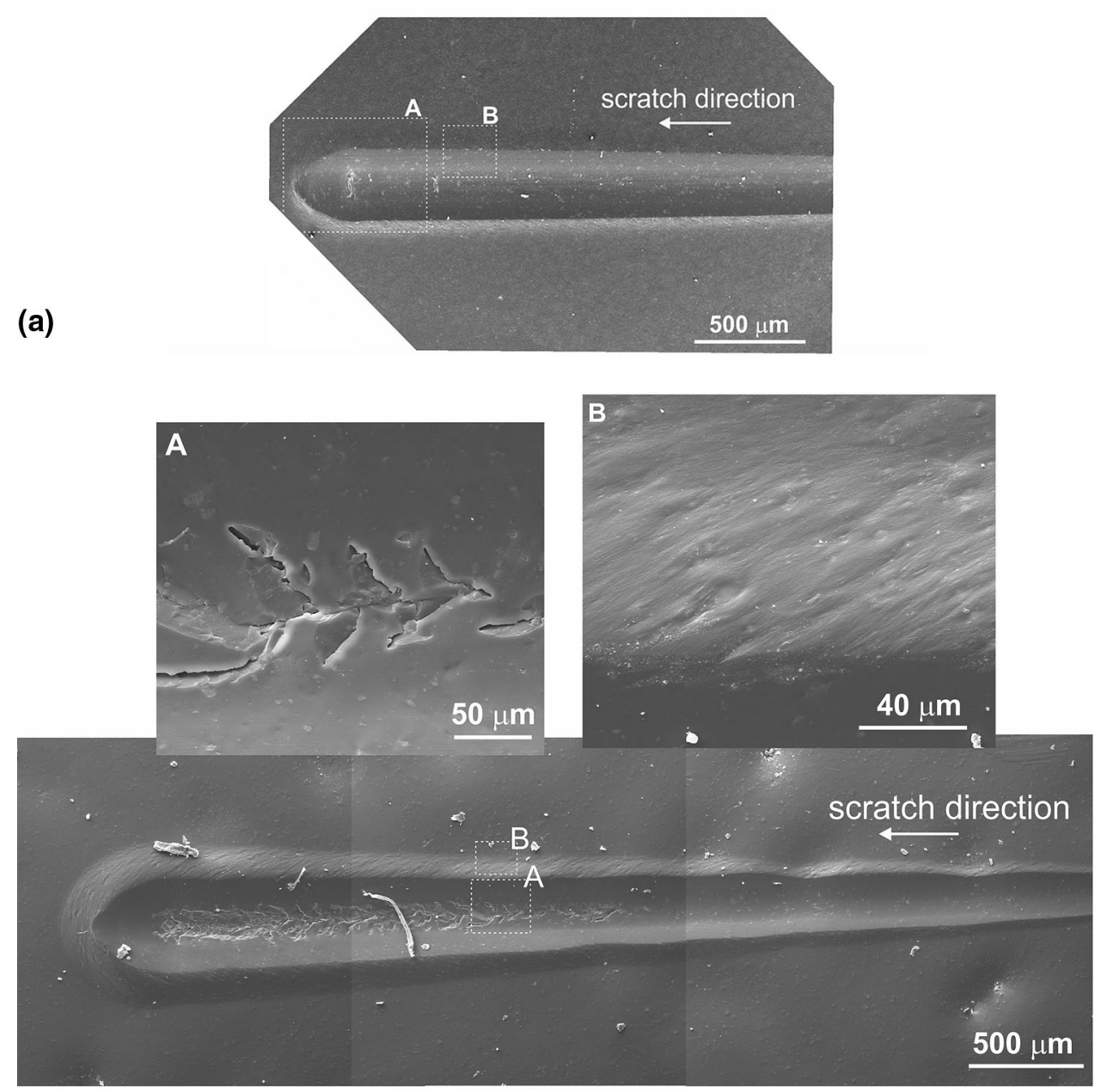

(b)

Fig. 11 SEM secondary electron images of the semi-crystalline (a) and amorphous (b) $\mathrm{Al}_{2} \mathrm{O}_{3} / \mathrm{PEEK} 708$ coating surface after the scratch test

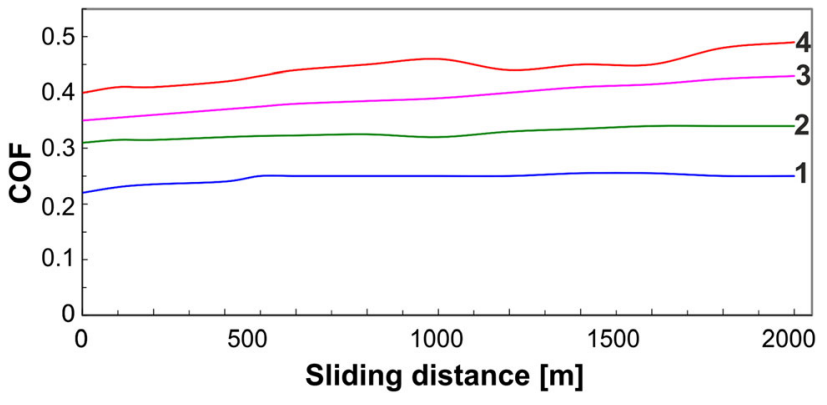

Fig. 12 Coefficient of friction of the amorphous and semicrystalline $\mathrm{Al}_{2} \mathrm{O}_{3} / \mathrm{PEEK} 708$ coatings at RT, 150 and $260{ }^{\circ} \mathrm{C}$ (1-semi-crystalline coating at RT, 2-amorphous coating at RT, 3 - semi-crystalline coating at $150{ }^{\circ} \mathrm{C}, 4$ - semi-crystalline coating at $\left.260{ }^{\circ} \mathrm{C}\right)$ particles did not reduce the scratch resistance of the coatings. The highest scratch resistance was demonstrated by those pure PEEK708 and composite $\mathrm{Al}_{2} \mathrm{O}_{3}$ /PEEK708 coatings whose hardness $(H)$ and modulus of elasticity $(E)$ were also the highest. Semi-crystalline coatings, both composite $\mathrm{Al}_{2} \mathrm{O}_{3}$ / PEEK708 $(H=0.35 \pm 0.03 \mathrm{GPa}, E=6.4 \pm 0.5 \mathrm{GPa})$ and pure PEEK708 $(H=0.32 \pm 0.02 \mathrm{GPa}, E=5.9 \pm 0.2 \mathrm{GPa}$ (Ref 19)), have a higher hardness and modulus of elasticity in comparison with coatings with amorphous structures. The presence of $\mathrm{Al}_{2} \mathrm{O}_{3}$ particles in the amorphous composite coatings with $H=0.22 \pm 0.02 \mathrm{GPa}$ and $E=6 \pm 0.4 \mathrm{GPa}$ also increased the micro-mechanical properties compared to the pure PEEK708 amorphous coating $(H=0.19 \pm 0.01 \mathrm{GPa}$, $E=4.5 \pm 0.2 \mathrm{GPa}(\operatorname{Ref} 19))$. The test results confirmed that the hardness and elastic modulus, as well as scratch resistance, of the semi-crystalline composite $\mathrm{Al}_{2} \mathrm{O}_{3}$ /PEEK708 coatings 

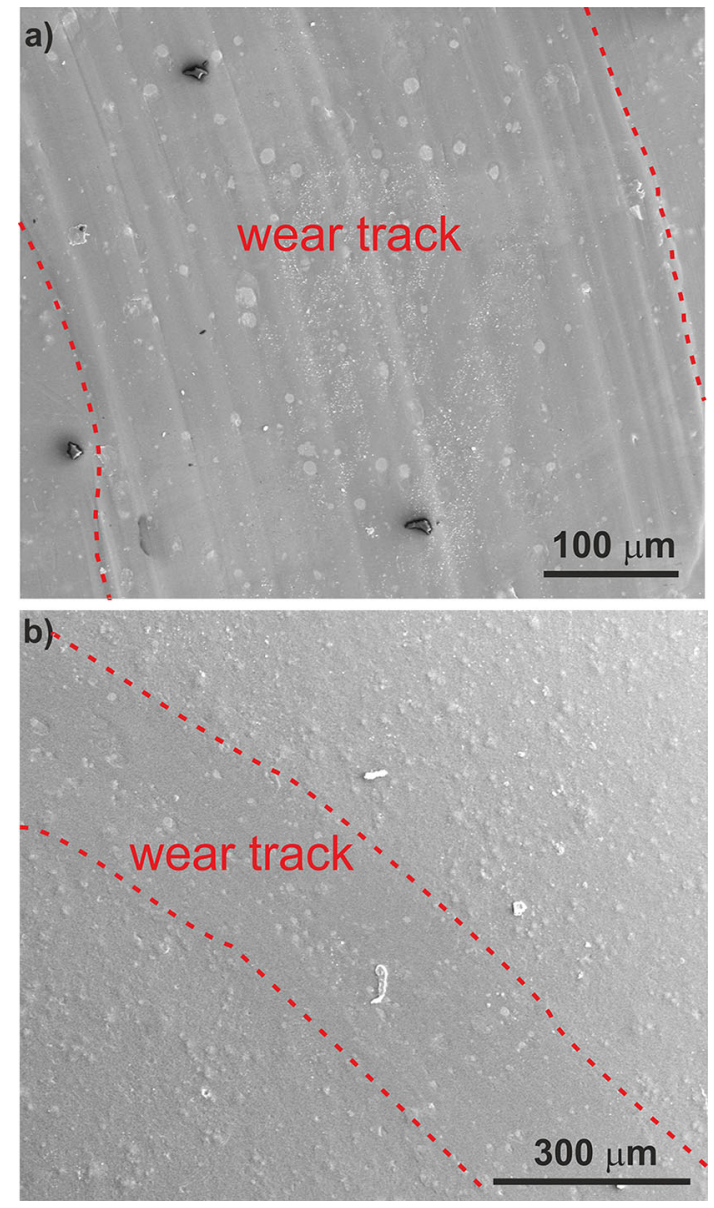

Fig. 13 SEM secondary electron images of the wear track in the amorphous (a) and semi-crystalline (b) $\mathrm{Al}_{2} \mathrm{O}_{3} /$ PEEK708 coating on the Ti-6Al-4V alloy after friction at RT

fabricated by EPD and post-heat treatment are at a higher level than those obtained elsewhere (Ref 34, 35).

The investigation has shown that the tribological properties of the coated alloy depended on the polymer structure and the ambient temperature of the friction pair. The test result analysis of the $\mathrm{Al}_{2} \mathrm{O}_{3} /$ PEEK 708 coatings after friction in non-lubricated sliding contact with an alumina ball at temperatures of RT, 150 and $260{ }^{\circ} \mathrm{C}$ was performed in comparison with the results of the pure PEEK708 coatings investigated in our earlier work (Ref 19). The friction process was stable and the increase in resistance to motion was caused by the progressive wear of the coatings and the increase in the abutting surface before the front of the ball. The COF of the semi-crystalline composite coating during friction at RT reached the value of 0.25 , while for the pure polymeric coating it was stabilized at the level of 0.3 (Ref 19). A similar effect, however, to a lower extent, was found for the composite and pure polymer coatings with an amorphous structure, where the average COF was 0.32 and 0.33 , respectively. The lower friction of the composite coating is the result of its greater stiffness and hardness, thus a smaller contact area during sliding with the ball. The stiffness of the polymer matrix decreased at $260{ }^{\circ} \mathrm{C}$, and during the friction with the ball, there was a large plastic deformation, which resulted in the highest COF equal to 0.4 (Fig. 12).

The wear process of both composite coatings, regardless of the test temperature, was mainly abrasive, as evidenced by
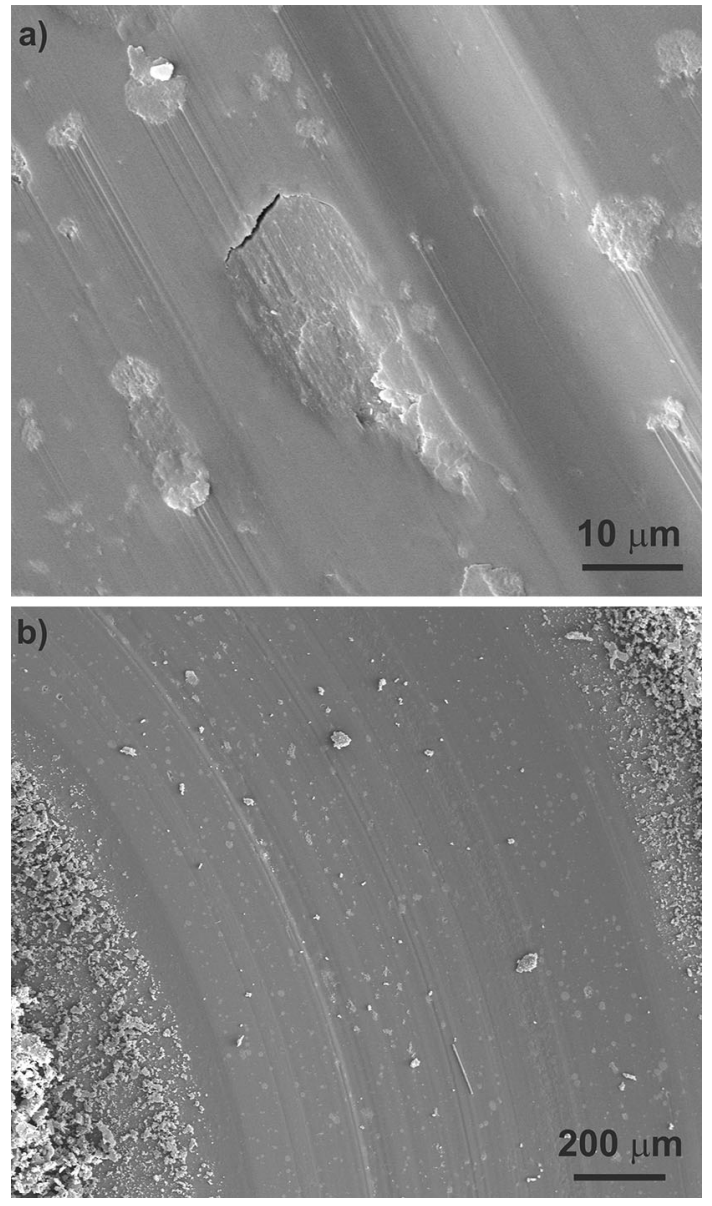

Fig. 14 SEM secondary electron images of the wear track in the semi-crystalline $\mathrm{Al}_{2} \mathrm{O}_{3} /$ PEEK 708 coating on the Ti-6Al-4V alloy after friction at $150{ }^{\circ} \mathrm{C}$ (a) and $260{ }^{\circ} \mathrm{C}(\mathrm{b})$

numerous scratches and wear debris present in the friction track (Fig. 13 and 14), especially at elevated temperatures (Fig. 14). The wear debris formed some agglomerates and their presence in the sliding contact increased the wear process of the composite coating by its plowing, as well as causing friction instability. A few cracks occurred in those places where the coating was thinnest as a result of local wear due to the tearing away of small pieces of material (Fig. 14a). The intensity of the abrasive wear as well as the plastic deformation of the coatings increased with the temperature in the environment of the friction pair. The specific wear rates of the amorphous and semi-crystalline $\mathrm{Al}_{2} \mathrm{O}_{3} / \mathrm{PEEK} 708$ coatings in comparison with the pure PEEK708 coatings after friction at RT, 150 and $260{ }^{\circ} \mathrm{C}$ are shown in Table 3. It was found that the wear resistance of the composite semi-crystalline coating after friction at RT was significantly higher compared to the pure PEEK708 coating. The wear rate of the $\mathrm{Al}_{2} \mathrm{O}_{3} /$ PEEK 708 coating equaled $0.47 \times 10^{-6} \mathrm{~mm}^{3} / \mathrm{Nm}$ and was over 6 times lower compared to the wear rate of the pure PEEK708 coating (Ref 19). However, during the test performed at the temperature of $150{ }^{\circ} \mathrm{C}$, and especially at $260{ }^{\circ} \mathrm{C}$, probably due to the plasticization of the PEEK708 polymer, the adhesion between the filler particles and the PEEK708 thermoplastic matrix degraded. For this reason, large amounts of hard particles appeared in the friction zone, which abraded the soft polymeric material. This phenomenon was favored by the occurrence of 
Table 3 Specific wear rate $\left(W_{v}\right)$ of the amorphous (a) and semi-crystalline (s-c) $\mathrm{Al}_{2} \mathrm{O}_{3} / \mathrm{PEEK} 708$ coatings compared to the pure PEEK708 coatings after friction at RT, 150 and $260{ }^{\circ} \mathrm{C}$

\begin{tabular}{lcccc}
\hline & \multicolumn{3}{c}{ Specific wear rate, $\boldsymbol{W}_{\mathbf{v}} \times \mathbf{1 0}^{\mathbf{- 6}}, \mathbf{~} \mathbf{m}^{\mathbf{3}} \mathbf{/ \mathbf { N m }}$} \\
\cline { 2 - 4 } Coating & At $\mathbf{R T}$ & \multicolumn{1}{c}{ At $\mathbf{1 5 0}{ }^{\circ} \mathbf{C}$} & At $\mathbf{2 6 0}{ }^{\circ} \mathbf{C}$ & Source \\
\hline $\mathrm{Al}_{2} \mathrm{O}_{3} /$ PEEK708 (s-c) & $0.47 \pm 0.03$ & $8.10 \pm 0.90$ & $33 \pm 2.80$ & Results of this work \\
$\mathrm{Al}_{2} \mathrm{O}_{3} /$ PEEK708 (a) & $0.92 \pm 0.15$ & $\cdots$ & $\ldots$ & Results of this work \\
PEEK708 (s-c) & $2.61 \pm 0.24$ & $3.19 \pm 0.21$ & $4.49 \pm 0.70$ & Ref 19 \\
PEEK708 (a) & $4.86 \pm 0.90$ & $\cdots$ & $\cdots$ & Ref 19 \\
\hline
\end{tabular}

$\mathrm{Al}_{2} \mathrm{O}_{3}$ agglomerates in the composite coating. Therefore, the highest wear was found for the semi-crystalline $\mathrm{Al}_{2} \mathrm{O}_{3} /$ PEEK708 coating after the test at $260{ }^{\circ} \mathrm{C}$, and its specific wear rate $W_{\mathrm{v}}=33 \times 10^{-6} \mathrm{~mm}^{3} / \mathrm{Nm}$ was seven times greater than $W_{\mathrm{v}}=4.49 \times 10^{-6} \mathrm{~mm}^{3} / \mathrm{Nm}$ for the semi-crystalline PEEK708 coating after friction in the same conditions (Ref 19). In comparison, the wear rate for the uncoated titanium alloy after friction at RT (versus $\mathrm{Al}_{2} \mathrm{O}_{3}$ ball at $5 \mathrm{~N}$ and $2000 \mathrm{~m}$ ) was huge and equaled $720 \times 10^{-6} \mathrm{~mm}^{3} / \mathrm{Nm}$.

\section{Conclusions}

1. The $\mathrm{Al}_{2} \mathrm{O}_{3} / \mathrm{PEEK} 708$ composite coatings were fabricated by anodic electrophoretic deposition and post-heat treatment. The EPD mechanism consisted of independent codeposition of PEEK 708 and $\mathrm{Al}_{2} \mathrm{O}_{3}$ particles onto titanium alloy substrates. The cooling rate after heating of the coated alloy significantly influenced the polymer structure. Slow cooling with a furnace resulted in the formation of a semi-crystalline structure with spherulitic morphology, whereas fast cooling in water generated an amorphous PEEK708 structure. The semi-crystalline coatings exhibited a more developed surface topography than the amorphous ones.

2. The PEEK structure significantly influenced the micromechanical properties and scratch resistance of the coatings. The semi-crystalline coatings revealed the highest hardness, $\quad 0.35 \pm 0.03 \mathrm{GPa}$, and Young's modulus, $6.4 \pm 0.5 \mathrm{GPa}$, as well as higher scratch resistance than the amorphous ones, for which the hardness was measured as $0.22 \pm 0.02 \mathrm{GPa}$ and elasticity modulus as $6 \pm 0.4 \mathrm{GPa}$.

3. The wear resistance of the semi-crystalline coating in dry sliding contact with an alumina ball was greater than the amorphous one. The wear rate at RT was $(0.47 \pm 0.03) \times 10^{-6}$ and $(0.92 \pm 0.15) \times 10^{-6}\left(\mathrm{~mm}^{3} /\right.$ $\mathrm{Nm}$ ) for the semi-crystalline and amorphous coatings, respectively, and for titanium alloy as much as $720 \times 10^{-6} \mathrm{~mm}^{3} / \mathrm{Nm}$. In turn, friction at elevated temperatures of 150 and $260{ }^{\circ} \mathrm{C}$ caused increased wear of the semi-crystalline coating and its wear rate reached a value of $(8.10 \pm 0.90) \times 10^{-6} \mathrm{~mm}^{3} / \mathrm{Nm}$ and $(33 \pm 2.80) \times 10^{-6} \mathrm{~mm}^{3} / \mathrm{Nm}$, respectively at 150 and $260{ }^{\circ} \mathrm{C}$. In spite of the wear increase at elevated temperatures, the $\mathrm{Al}_{2} \mathrm{O}_{3} /$ PEEK 708 coatings protected the alloy well against frictional wear both at RT and elevated temperatures of 150 and $260{ }^{\circ} \mathrm{C}$. Both the amorphous and semi-crystalline coatings reduced the $\mathrm{COF}$ of the titanium alloy; however, the semi-crystalline coating was more effective.

4. Both types of coating, amorphous and semi-crystalline, increased the corrosion resistance of the alloy in the $\mathrm{NaCl}$ solution. However, the semi-crystalline coating exhibited better corrosion resistance compared to the amorphous coating (polarization and impedance parameters). This result is probably the effect of significantly better adhesion to the substrate material compared to the amorphous coating.

\section{Acknowledgments}

This work was supported by the National Science Centre, Poland (Decision No DEC-2016/21/B/ST8/00238). The authors appreciate the valuable contributions of Dr M. Gajewska (ACMiN AGH) for FIB lamella preparation, DSc A. Kopia for XRD investigation and G. Elżbieciak, MSc, for the contribution to EPD and zeta potential measurement.

\section{Open Access}

This article is distributed under the terms of the Creative Commons Attribution 4.0 International License (http://creativecommons.org/ licenses/by/4.0/), which permits unrestricted use, distribution, and reproduction in any medium, provided you give appropriate credit to the original author(s) and the source, provide a link to the Creative Commons license, and indicate if changes were made.

\section{References}

1. S.-J. Park and M.-K. Seo, Ed., Interface Science and Composites, Chapter 6, Vol 18, Elsevier, Amsterdam, 2011, p 431-499

2. K. Steven and J. Devine, PEEK Biomaterials In Trauma, Orthopedic and Spinal Implants, Biomaterials, 2007, 28, p 4845-4869

3. G. Pan, Q. Guo, W. Zhang, and A. Tian, Fretting Wear Behaviors of Nanometer $\mathrm{Al}_{2} \mathrm{O}_{3}$ and $\mathrm{SiO}_{2}$ Reinforced PEEK Composites, Wear, 2009, 266, p 1208-1215

4. P.J. Rae, E.N. Brown, and E.B. Orler, The Mechanical Properties of Poly(Ether-Ether-Ketone) (PEEK) with Emphasis on the Large Compressive Strain Response, Polymer, 2007, 48, p 598-615

5. A.K. Kadiyala, J. Bijwe, and P. Kalappa, Investigations on Influence of Nano and Micron Sized Particles of SiC on Performance Properties of PEEK Coatings, Surf. Coat. Technol., 2018, 334, p 124-133

6. J. Song, Y. Liu, Z. Liao, S. Wang, R. Tyagi, and W. Liu, Wear Studies on $\mathrm{ZrO}_{2}$-Filled PEEK as Coating Bearing Materials for Artificial Cervical Discs of Ti6Al4V, Mater. Sci. Eng. C, 2016, 69, p 985-994 
7. J. Tharajak, T. Palathai, and N. Sombatsompop, Morphological and Physical Properties and Friction/Wear Behavior of h-BN Filled PEEK Composite Coatings, Surf. Coat. Technol., 2015, 273, p 20-29

8. M. Hedayati, M. Salehi, R. Bagheri, M. Panjepour, and F. Naeimi, Tribological and Mechanical Properties of Amorphous and Semicrystalline $\mathrm{PEEK} / \mathrm{SiO}_{2}$ Nanocomposite Coatings Deposited on the Plain Carbon Steel by Electrostatic Powder Spray Technique, Prog. Org. Coat., 2012, 74, p 50-58

9. G. Zhang, H. Liao, H. Li, C. Mateus, J.-M. Bordes, and C. Coddet, On Dry Sliding Friction and Wear Behaviour of PEEK and PEEK/SiCComposite Coatings, Wear, 2006, 260, p 594-600

10. G. Zhang, W.Y. Li, M. Cherigui, C. Zhang, H. Liao, J.-M. Bordes, and C. Coddet, Structures and Tribological Performances of PEEK (PolyEther-Ether-Ketone)-Based Coatings Designed for Tribological Application, Prog. Org. Coat., 2007, 60, p 39-44

11. G. Zhang, S. Guessasma, H. Liao, C. Coddet, and J.-M. Bordes, Investigation of Friction and Wear Behaviour of SiC-Filled PEEK Coating Using Artificial Neural Network, Surf. Coat. Technol., 2006, 200, p 2610-2617

12. I. Corni, N. Neumann, S. Novak, K. König, P. Veronesi, Q. Chen, M.P. Ryan, and A.R. Boccaccini, Electrophoretic Deposition of PEEK-Nano Alumina Composite Coatings on Stainless Steel, Surf. Coat. Technol., 2009, 203, p 1349-1359

13. A.R. Boccaccini, C. Peters, J.A. Roether, D. Eifler, S.K. Misra, and E.J Minay, Electrophoretic Deposition of Polyetheretherketone (PEEK) and PEEK/Bioglass ${ }^{\circledR}$ Coatings on NiTi Shape Memory Alloy Wires, $J$. Mater. Sci., 2006, 41, p 8152-8159

14. T. Moskalewicz, S. Zimowski, A. Zych, A. Łukaszczyk, K. Reczyńska, and E. Pamuła, Electrophoretic Deposition, Microstructure and Selected Properties of Composite Alumina/Polyetheretherketone Coatings on the Ti-13Nb-13Zr Alloy, J. Electrochem. Soc., 2018, 165(3), p D116-D128

15. T. Moskalewicz, A. Zych, A. Kruk, A. Kopia, S. Zimowski, M. Sitarz, and L. Cieniek, Electrophoretic Deposition and Microstructure Development of $\mathrm{Si}_{3} \mathrm{~N}_{4} /$ Polyetheretherketone Coatings on Titanium Alloy, Surf. Coat. Technol., 2018, 350, p 633-647

16. H.B. Qiao, Q. Guo, A.G. Tian, G.L. Pan, and L.B. Xu, A Study on Friction and Wear Characteristics of Nanometer $\mathrm{Al}_{2} \mathrm{O}_{3} / \mathrm{PEEK}$ Composites Under the Dry Sliding Condition, Tribol. Int., 2007, 40, p 105110

17. A.R. Boccaccini, S. Keim, R. Ma, Y. Li, and I. Zhitomirsky, Electrophoretic Deposition of Biomaterials, J. R. Soc. Interface, 2010, 7, p S581-S613

18. M. Ammam, Electrophoretic Deposition Under Modulated Electric Fields: A Review, RSC Adv., 2012, 2, p 7633-7646

19. A. Kruk, S. Zimowski, A. Łukaszczyk, Ł. Cieniek, and T. Moskalewicz, The Influence of Heat Treatment on the Microstructure, Surface Topography and Selected Properties of PEEK Coatings Electrophoretically Deposited on the Ti-6Al-4V Alloy, Prog. Org. Coat., 2019, 133, p 180-190

20. D.J. Blundell and B.N. Osborn, The Morphology of Poly(Aryl-EtherEther-Ketone), Polymer, 1983, 24, p 953-958

21. O. Yoda, The Radiation Effect on Non-crystalline Poly(Aryl-EtherKetone) as Revealed by X-Ray Diffraction and Thermal Analysis, Polym. Commun., 1984, 25, p 238-240

22. M.A. Ur Rehman, F.E. Bastan, Q. Nawaz, W.H. Goldmann, M. Maqbool, S. Virtanen, and A.R. Boccaccini, Electrophoretic Deposition of Lawsone Loaded Bioactive Glass (BG)/Chitosan Composite on
Polyetheretherketone (PEEK)/BG Layers as Antibacterial and Bioactive Coating, J. Biomed. Mater. Res. Part A, 2018, 106(12), p 31113122

23. M.A. Ur Rehman, F.E. Bastan, B. Haider, and A.R. Boccaccini, Electrophoretic Deposition of PEEK/Bioactive Glass Composite Coatings for Orthopedic Implants: A Design of Experiment (DoE) Study, Mater. Des., 2017, 130, p 223-230

24. F.E. Baştan, M.A. Ur Rehman, Y.Y. Avcu, E. Avcu, F. Üstel, and A.R. Boccaccini, Electrophoretic Co-deposition of PEEK-Hydroxyapatite Composite Coatings for Biomedical Applications, Colloids Surf. B, 2018, 169, p 176-182

25. G. Zhang, H. Liao, H. Yu, V. Ji, W. Huang, S.G. Mhaisalkar, and C. Coddet, Correlation of Crystallization Behavior and Mechanical Properties of Thermal Sprayed PEEK Coating, Surf. Coat. Technol., 2006, 200, p 6690-6695

26. G. Zhang, H. Liao, M. Cherigui, J.P. Davim, and C. Coddet, Effect of Crystalline Structure on the Hardness and Interfacial Adherence of Poly(Ether-Ether-Ketone) Coating, Eur. Polym. J., 2007, 43, p 10771082

27. J. Li, H. Liao, and C. Coddet, Friction and Wear Behavior of FlameSprayed PEEK Coatings, Wear, 2002, 252, p 824-831

28. C. Zhang, G. Zhang, J.I. Vincent, H. Liao, S. Costil, and C. Coddet, Microstructure and Mechanical Properties of Flame-Sprayed PEEK Coating Remelted by Laser Process, Prog. Org. Coat., 2009, 66, p 248-253

29. T. Moskalewicz, B. Wendler, S. Zimowski, B. Dubiel, and A. CzyrskaFilemonowicz, Microstructure, Micro-mechanical and Tribological Properties of the nc-WC/a-C nanocomposite Coatings Magnetron Sputtered on Non-hardened and Oxygen Hardened Ti-6Al-4V Alloy, Surf. Coat. Technol., 2010, 205, p 2668-2677

30. A. Sak, T. Moskalewicz, S. Zimowski, Ł. Cieniek, B. Dubiel, A. Radziszewska, M. Kot, and A. Łukaszczyk, Influence of Polyetheretherketone Coatings on the Ti-13Nb-13Zr Titanium Alloy's Bio-tribological Properties and Corrosion Resistance, Mater. Sci. Eng. $C, 2016,63$, p 52-61

31. J. Loch, H. Krawiec, and A. Łukaszczyk, Influence of simulated Physiological Solution to Corrosion Resistance of Ti6Al4V and Ti10Mo4Zr Alloys and Alloying Elements, Arch. Foundry Eng., 2014, 14(4), p 89-94 ((in Polish))

32. E. Mc Cafferty and G.K. Hubler, Electrochemical Behavior of Palladium Implanted Titanium, J. Electrochem. Soc., 1978, 125(11), p 1892-1893

33. H. Krawiec, V. Vignal, J. Loch, and P. Erazmus-Vignal, Influence of Plastic Deformation on the Microstructure and Corrosion Behavior of Ti-10Mo-4Zr and Ti-6Al-4V Alloys in the Ringer's Solution at $37{ }^{\circ} \mathrm{C}$, Corros. Sci., 2015, 96, p 160-170

34. J. Song, Z. Liao, S. Wang, Y. Liu, W. Liu, and R. Tyagi, Study on the Tribological Behaviors of Different PEEK Composite Coatings for Use as Artificial Cervical Disk Materials, J. Mater. Eng. Perform., 2016, 25(1), p 116-129

35. M.C. Kuo, C.M. Tsai, J.C. Huang, and M. Chen, PEEK Composites Reinforced by Nano-sized $\mathrm{SiO}_{2}$ and $\mathrm{Al}_{2} \mathrm{O}_{3}$ Particulates, Mater. Chem. Phys., 2005, 90(1), p 185-195

Publisher's Note Springer Nature remains neutral with regard to jurisdictional claims in published maps and institutional affiliations. 